\title{
Parental attitude towards sex education at the lower primary in Ghana
}

\author{
Kingsley Nyarko ${ }^{1}$, Kobina Impraim Adentwi ${ }^{3}$, Maxwell Asumeng ${ }^{1}$, Linda Dede Ahulu ${ }^{2}$ \\ ${ }^{1}$ University of Ghana, Psychology Department, P. O. Box LG 84, Legon, Accra, Ghana \\ ${ }^{2}$ AngloGold Ashanti Schools, Child Counselor, P. O. Box 10, Obuasi Adansi, Ghana \\ ${ }^{3}$ University of Education, Winneba, College of Technology Education, Department of Interdisciplinary Studies, P. O. Box 1277, Kumasi, \\ Ghana
}

\section{Email address:}

kingpong73@yahoo.com (K. Nyarko), adentwi@yahoo.com (K. I. Adentwi), masumeng@ug.edu.gh (M. Asumeng), lindaahulu@gmail.com (L. D. Ahulu)

\section{To cite this article:}

Kingsley Nyarko, Kobina Impraim Adentwi, Maxwell Asumeng, Linda Dede Ahulu. Parental Attitude towards Sex Education at the Lower Primary in Ghana. International Journal of Elementary Education. Vol. 3, No. 2, 2014, pp. 21-29. doi: $10.11648 /$ j.ijeedu.20140302.11

\begin{abstract}
This study investigates parental attitude towards sex education at the lower primary level of education in Ghana. In all 100 parents ranging from 20 to 60 years, with diverse socio-economic backgrounds consisting of 64 males and 36 females where sampled for the study. Out of this number, 63\% reside in urban areas, whereas $37 \%$ reside in rural areas. The results indicate that about $58 \%$ of parents have an unfavourable attitude towards sex education in lower primary schools. Unsurprisingly, all the parents who held unfavourable attitude towards sex education said that children are too young for sex education at the lower primary school level. However, of the parents who held favourable attitude; $81 \%$ indicated that children are exposed a lot these days. $17 \%$ admitted that sex education will be helpful to the children and $2 \%$ said children ask questions about sex anyway and needed to be provided with answers. Finally, the results showed that there is no gender difference in parental attitude towards sex education, as well as no residency difference about sex education. However, there was a difference in parental attitude in connection to their educational level. The implications of the findings from this research are discussed.
\end{abstract}

Keywords: Sex Education, Parental Attitude, Lower Primary, Children

\section{Introduction}

In Ghana, a confluence of cultural, religious and geographical factors creates a sensitive environment where issues of sexual and reproductive health have remained highly a taboo for decades (Mack, 2011). Sexual health is an important determinant of productivity and national development everywhere. Yet, the mere mention of "Sex" seems to evoke itchy feelings among both the young and old. Adults in the Ghanaian Society have usually refrained from discussing sexual matters with the young. Traditionally, children are brought up with strict discipline and fear and are punished for questioning their parents, especially the girls (Brocato \& Dwamena- Aboagye, 2007). Consequently, young people are afraid to ask questions relating to sexual issues as they would be seen as "disrespectful" and "disobedient-" sexual issues are seen as topics for adult discussions only.
Meanwhile, as shown by the 2000 population and housing census, Ghana is indeed religious. With $69 \%$ Christians and $15.6 \%$ Muslims, people try to abide by moral doctrines of their respective religions. The church, for example often gives "moral education" and not sex education and to Muslim parents, sex is a taboo subject (Athar, 1996). Sex education to children is thus associated with encouraging immorality; in fact, the religious view has been that it could make adolescents who are not active in sexual activities to start sexual experimentation (Ankomah, 2001). However, this religious view is not supported by empirical evidence. The evidence is that children who are not introduced to sex education are more likely to experience teenage pregnancy. In fact, "educational authorities that didn't provide sex education, such as New York, had the highest rates of teen pregnancy" (Briggs, 2005: 2).

Sexuality, rather than morality, has become the custom and young people are not excluded from this exposure 
(Klemp, Moore, \& Moore, 2003). Adults today may rightfully describe the youth as morally wayward. The truth of the matter, however, is that due to the emergence of globalization and torrent of sex-related information available to children via media, foreign influence and technology (Lim \& Kui, 2006), the culture of silence is impossible to sustain. Parents and teachers involved in sex education have divergent views and this poses a lot of problems. To some, sex education is a strong incest taboo (Macleod, 1999; Kunene, 1988) and should be discouraged. It is perceived by others as one of those social forces that come with modernization to break down the moral fabric of the entire society (Marion \& McCabe, 1990). Some also strongly believe that children are too young and not sexually active (O'Regan, 2001).

However, children of today constantly surprise their parents with their questions (Hyder \& DeLamater, 1997) and gestures. Why won't they, when sexual images confront them every day? Nowadays, it is easy to identify sexual images everywhere: in computer games, on billboards, newspapers, and television. Music videos are so sexually explicit, female dancers are almost naked and with mobile phones and computers everywhere, pornography can be accessed with a click. Again, young people are having sexual intercourse at much younger ages - i.e. between 8 and 17 years (Ansah-Addo, 2005); sometimes even younger (Naidoo, 2001; Small \& Luster, 1994; Stack, 1994). In a recent survey by Lim and Kui (2006), boys as young as nine years old said they have had sexual experiences.

Sex education aims to reduce risks of potentially negative outcomes from sexual behaviour, equips learners with life skills, and reduces the high level of drop out and unwanted pregnancies. It provides knowledge on how to prevent transmission of diseases such as HIV/ AIDS and other health problems (Steinberg, 1996). Historically, the task of instructing about sex has been seen as the responsibility of parents. Today, the term usually refers to classroom lessons about sex taught in schools. Sex education also aims at contributing to young people's positive experience of their sexuality by enhancing the quality of their relationships. It offers sexuality programmes aimed at providing accurate information about human sexuality for young people to develop and understand their values, attitudes and beliefs about sexuality. This, according to Forrester (2009), is a means by which they are helped to protect themselves against abuse, exploitation, unintended pregnancies and sexually transmitted diseases.

Undeniably, the issue of sex education in schools has been very controversial with respect to the stage at which it should begin. In his essay, "Sex Education in Ghanaian Society: The Skeleton in the Cupboard," Osei (2009) illustrates how his mother lost her teaching job in 2004 for teaching her class one (1) pupils the parts of the body. According to him, the Ghanaian government's attitude toward sex education is best described as ambivalent because though the subject is officially part of the school curricula, it is not "effectively taught" in practice. Ankomah (2001) explains that governments want to satisfy the religious critics in the society. In United States, critics have posed some questions about the state's usurpation of parental rights and responsibilities, the adequacy of ethical instruction and the wisdom of imparting sexual information to immature minds (Sanders, 2008). But, the intriguing question is this: do parents find it necessary to introduce their children, especially those at the lower levels of education to sex education?

Attitude towards sex education differs from one group to another depending on many factors like dominant perceptions, social belief systems, religious factors, family socialization and cultural set up within which learners grow up (Gallagher \& Gallagher, 1996). It also depends on the attitude of teachers who will be responsible for the formal aspects (Nokwe, 1991) and principally parents who are a child's first point of contact and play a vital part in the informal education of the learner. This is why parental attitude on the topic of sex education is very important. Our cultures' hesitant attitude about sexuality is evident in the limitations placed on sex education in primary and secondary schools and often in its total absence from the curriculum (Baron \& Byme, 1994). There are many studies that have examined different factors related to early sexual activity (Small, Luster, \& Stack, 1994), community and peer group characteristics on sexual behaviour (Billy, Brewster, \& Grady, 1994) and secondary school learners' attitude towards sex education (Majova, 2002).

Also studies on Sex education have usually concentrated on adolescents, basic School learners and senior secondary school learners. From the numerous literatures reviewed for this study, it is evident that no studies have been conducted in the field of parental attitude towards sex education with lower primary school children as the main focus in the country. This study is therefore the first of its kind to fill the gap in studies on sex education that have neglected lower primary schools where the solid foundation for formal education is built.

In connection to the above deduced arguments regarding sex education, the study was conducted to find out 1 . The attitude of Ghanaian parents towards sex education at the lower primary level of education, 2. The appropriate level for the onset of sex education, 3.Parental gender in relation to parent-child communication on sexual matters, 4 . The socialization agent responsible for the provision of sex education, and 5. Whether residence determines the provision of sex education. Flowing from the above, the following hypotheses were proposed: 1. Parents in Ghana will have a negative attitude towards sex education, 2 . Parents are likely to favour sex education at the high school level, 3. Mothers will have a more positive attitude towards sex education than fathers, 4. Mothers will communicate more with their children on sexual matters than fathers, 5 . Urban parents will have a more favourable attitude towards sex education than their rural counterparts, and 6. Parents with higher education will favour sex education at lower 
primary schools than parents with lower education.

\section{Method}

\subsection{Sample}

The sample for the study was drawn on purposively selected participants of parents of children at the lower primary school from AngloGold Ashanti school (Urban) and Dompoase (Rural) all at the Obuasi Municipality. Hundred (100) parents were sampled for the research: $64 \%$ of the participants were parents of lower primary school children in AngloGold Ashanti School (Urban) and 36\% from Dompoase (rural). In all 64 males and 36 females were sampled for this study. Out of the 112 questionnaires administered, 12 were destroyed and discarded because of missing values.

\subsection{Procedure}

An introductory letter was taken to the AngloGold Ashanti School by the researchers for approval and permission to conduct the research. Upon approval a date was scheduled to visit the AngloGold Ashanti School during a PTA meeting. For Dompoase, a rural community, the researchers went round the community in search for parents whose children were in lower primary school. The participants were briefed on the research before the questionnaires were given out to them to fill out. Respondents were assured that the information would be treated as strictly confidential as possible. They were asked not to write their names on the questionnaire in assurance of anonymity and were reminded that although their full participation was needed, participation was voluntary. Respondents were told that the questionnaire should be completed without discussion with other respondents. They were told also to feel free because there was no right or wrong answers. Assistance was provided by 3 tertiary students who were trained by the researchers to explain and help parents to fill out the questionnaires. The administration of the questionnaire lasted for three days: 1 day at AngloGold Ashanti school and 2 days at the Dompease community.

\subsection{Measures}

The research design used for the study was a survey which necessitated the use of a questionnaire in collecting the data. It asked for specific factual information about parental attitude towards sex education at the basic level of education in the country. The demographic variables that were used for this present study are age, gender, grade, and family structure.

\subsubsection{Appropriate Level for Sex Education}

Parents were asked a close-ended question to indicate the most appropriate level for the onset of sex education. The options provided were, lower primary level, upper primary level, and senior high school level. Lower primary level was coded as 1 , primary school level was coded as 2 , and senior high school level was coded as 3 .

\subsubsection{Parent-Child Communication on Sexual Matters}

In collecting data on this variable, parents were asked the frequency with which they discuss sexual matters with their children. The options provided were never, sometimes, and often. They were coded 1, 2, and 3 respectively.

\subsubsection{Attitude of Parents towards Sex Education (Jasmine Sui, 1994)}

The main instrument for the study was adapted from the attitude of parents towards sex education for students design by Jasmine Sui (1994) of the P.G. Department of Home sciences at the University of Jammu. It measures the attitude of parents towards imparting sex education to adolescent girls on a 5-point Likert scale ranging from 1strongly disagree to 5-strongly agree. The higher the score, the less favourable the parent is towards sex education. It was modified to suit the Ghanaian lower primary school pupil parent's understanding given that it was originally made to suit parents of Indian adolescent girls. It contains 15 questions; sample items include "sex education enlightens lower primary learners' view about sex," "sex education can make children immoral." It has a reliability of 0.78 .

\subsection{Statistical Treatment of the Data}

The analysis of the data was done by using multiple statistical methods. Descriptive statistics was used to analyze the demographic variables and the composition of parental attitude towards sex education, appropriate level for the introduction of sex education, and parent-child communication on sexual issues by using frequencies and percentages. Again, test statistics (independent t-test) was used to find out differences in gender in relation to attitudes towards sex education, as well as nature of residency in relation to sex education. Finally, analysis of variance (oneway Anova) was used to find out the differences in the means of parental educational level and their attitudes towards sex education.

\section{Results}

\subsection{Parental Attitude towards Sex Education}

Table 1. parents' attitude towards sex education in lower primary schools $(N=100)$

\begin{tabular}{llll}
\hline Favourable & Percentage & Unfavourable & Percentage \\
\hline 42 & $42 \%$ & 58 & $58 \%$ \\
\hline
\end{tabular}

The result as captured on the table above (table 1) shows that majority of parents $(58 \%)$ has unfavourable attitude towards sex education; these parents disagree to teaching sex education at the lower primary school level. On the other hand, $42 \%$ of parents support sex education in lower primary schools. 


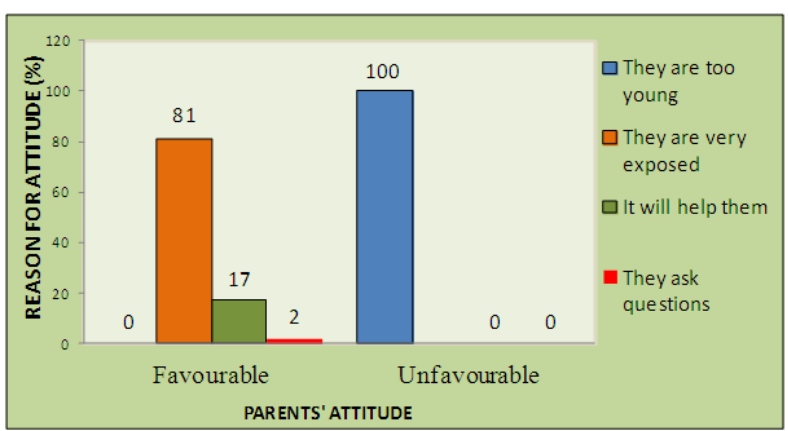

Figure 1. Reasons that underlie parental attitude towards sex education in lower primary schools

When asked about the reasons for their attitude, all the parents $(100 \%)$ who hold unfavourable attitude said that children are too young for sex education at the lower primary school level. Of the parents who hold favourable attitudes; $81 \%$ said that children are exposed a lot these days. $17 \%$ admitted that sex education will be helpful to the children, and $2 \%$ said children ask questions about sex and needed to be provided with answers.

\subsection{Appropriate Level for the Onset of Sex Education}

The figure below (figure 2) shows that $58 \%$ of parents believe that sex education should start at the upper primary level; $30 \%$ are in support of sex education at the lower primary level and $12 \%$ of them are of the view that sex education should begin at the high school level (JHS-SHS). In all, $70 \%$ of parents prefer that sex education should start after lower primary level.

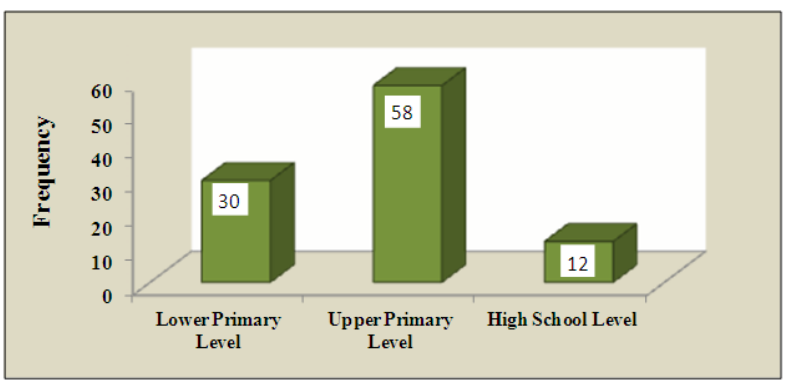

Figure 2. Appropriate level for onset of sex education in schools

\subsection{Parent Gender and Parent-Child Communication}

The result of this study as depicted on (figure 3) shows that $8 \%$ of fathers and $27 \%$ of mothers often talk to their children about sex. $54 \%$ of fathers and $38 \%$ of mothers have never talked to their children about sex. 35\% of mothers and $38 \%$ of fathers said they sometimes talked to their children about sex. Again, as shown on (figure 4), $46.7 \%$ of fathers and $51.7 \%$ of mothers said they were comfortable talking to their children about sex. However, $53.3 \%$ of fathers and $48.3 \%$ of mothers admitted discomfort in talking to their children about sex.

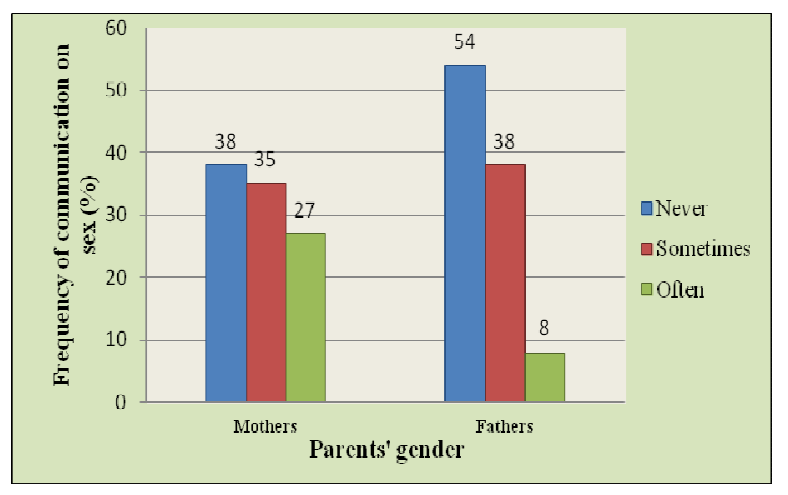

Figure 3. Parental gender and Frequency of Parent - Child Communication on Sex

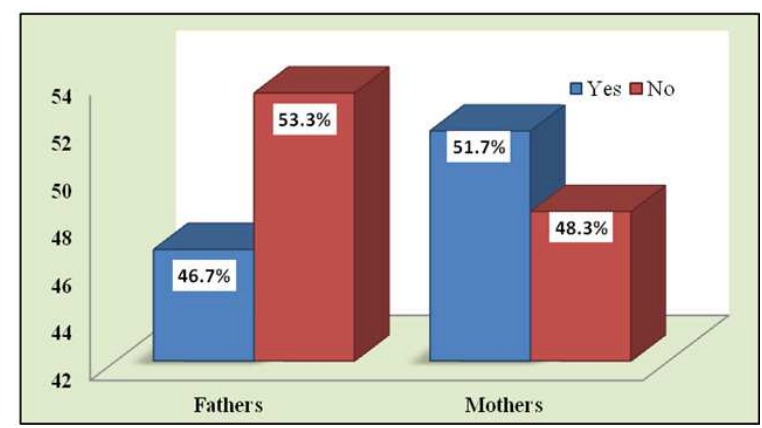

Figure 4. Are you comfortable talking about sex with your child

\subsection{Provision of Sex Education}

When asked who was responsible for providing sex education to the child, $45 \%$ of fathers and $39 \%$ of mothers said it should be the responsibility of both parents. $24 \%$ of fathers and $11 \%$ of mothers said both parents and teachers. As many fathers as mothers (14\% and $11 \%)$ said mothers and teachers respectively. No father $(0 \%)$ and $8 \%$ of mothers said it was fathers. More mothers (17\%) than fathers $(6 \%)$ said religious bodies are responsible and all parents rejected friends as the right source of sex education.

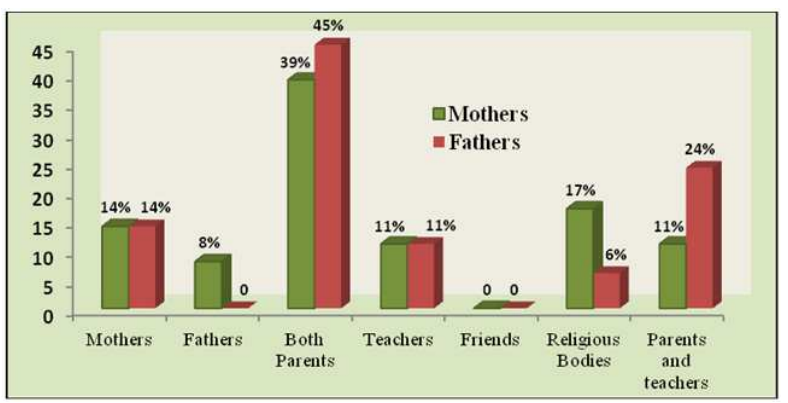

Figure 5. Who must provide sex education for the child?

\subsection{Parental Gender as a Function of Sex Education}

The table below (table 2) shows the mean attitude scores on attitude towards sex education of fathers and mothers whose children are in lower primary school. The Independent-samples t-test indicates that there is no difference between fathers' attitude towards sex education at the lower primary school $(\mathrm{M}=1.61, \mathrm{SD}=.49)$ and 
mothers' attitude towards sex education at the lower primary school $(\mathrm{M}=1.53, \mathrm{SD}=.51), \mathrm{t}(98)=0.788, \mathrm{p}>0.05$.

Table 2. Mean Attitude Scores and Standard Deviations on Sex education by Gender of Parents $(N=100)$

\begin{tabular}{llllll}
\hline Gender & N & Mean & Std. Deviation & t & sig \\
\hline Fathers & 64 & 1.61 & .49 & & \\
& & & & 0.788 & 0.433 \\
Mothers & 36 & 1.53 & .51 & & \\
\hline
\end{tabular}

$\mathrm{p}>0.05$

\subsection{Residency as a Determinant of Sex Education}

The table below (table 3 ) shows the mean and standard deviation scores of parents who reside in urban and rural areas. The Independent-samples t-test shows that there is no difference in attitude towards sex education between parents who reside in rural areas $(\mathrm{M}=1.70, \mathrm{SD}=.46)$ and those who dwell in urban areas $(\mathrm{M}=1.51, \mathrm{SD}=.50), \mathrm{t}(98)$ $=1.921, \mathrm{p}>0.05$.

Table 3. Mean Attitude Scores and Standard Deviations on Sex education by Residence of Parents $(N=100)$

\begin{tabular}{llllll}
\hline Residence & N & Mean & Std. Deviation & t & Sig \\
\hline Rural & 37 & 1.70 & .46 & & \\
& & & & 1.921 & 0.058 \\
Urban & 63 & 1.51 & .50 & & \\
\hline
\end{tabular}

$\mathrm{p}>0.05$

\subsection{Parental Educational Level as a Determinant of Sex Education}

The tables below (tables 4 \& 5) show the mean differences of parental level of education and their attitude towards sex education. The result shows that there is a difference among parents who have tertiary education (M $=1.49, \mathrm{SD}=0.504)$, those with junior high school education $(\mathrm{M}=1.58, \mathrm{SD}=0.515)$, and senior high school education $(\mathrm{M}=1.80, \mathrm{SD}=0.408) ; \mathrm{F}(2,97)=3.632$, $\mathrm{p}$ $<.030$.

Table 4. Mean attitude scores and standard deviations on sex education by education level of Parents $(N=100)$

\begin{tabular}{llll}
\hline Education level & $\mathbf{N}$ & Mean & Std. Deviation \\
\hline J.H.S & 12 & 1.58 & .515 \\
S.H.S & 25 & 1.80 & .408 \\
Tertiary & 63 & 1.49 & .504 \\
\hline
\end{tabular}

Table 5. One-Way Analysis of Variance for Education level of Parents

\begin{tabular}{llllll}
\hline & $\begin{array}{l}\text { Sum of } \\
\text { Squares }\end{array}$ & df & $\begin{array}{l}\text { Mean } \\
\text { Square }\end{array}$ & F & Sig \\
\hline Between & 1.697 & 2 & .849 & 3.632 & .030 \\
Groups & 22.663 & 97 & .234 & & \\
Within Groups & 24.360 & 99 & & & \\
Total & & & & \\
\hline
\end{tabular}

$\mathrm{P}<0.05$

\section{Discussion and Recommendations}

The results of the study clearly show that Ghanaian parents have an unfavourable attitude towards sex education at the lower primary level of education. Majority (58\%) of parents are not in support of sex education at lower primary schools. This finding supports that of (Malajan \& Sharma, 2005) that mothers were unwilling to talk about sex education to their daughters because it was embarrassing to discuss issues about sex. According to the authors, these mothers avoided the mention of sex in their daily interaction with their children. Reasons proffered were that sex is still considered a taboo in the Indian society, and more importantly, these parents lack the scientific knowledge about the topic. Hovell (1994) looking at the influence of the family on adolescents' sexual behaviour revealed that conservative maternal attitude about sex delay the development of sex behavior. Interestingly the finding of this study contradicts previous studies which recorded more favourable than unfavourable attitudes (Price, Dake, Kirchofer, \& Telljohann, 2003; McKay, Pietrusiak, \& Holowaty, 1998; Majova, 2002; Hyder \& DeLamater, 1997). Parents in Ghana therefore consider children's ages as important when it comes to what they must know about sex.

All unfavourably disposed parents held that the children were too young. $81 \%$ of parents with favourable attitudes said children are very exposed to sexual information these days. Some parents said: "They see and hear so much on television, internet, friends, books, etc," "They must know the changes that will occur in and outside their bodies as they grow up and understand what those changes mean," "It will help them to know the implications of early sexual activity like unwanted pregnancies, abortions, school dropouts and AIDS and this will cause them to abstain from early sex." $17 \%$ of the parents believed that sex education will help children in dealing with several aspects of growing up. $2 \%$ of parents agreed that children asked many questions and deserve to have appropriate answers.

The second hypothesis that states that parents are likely to prefer sex education at the high school level was supported. Although, 30\% of parents approved of sex education at lower primary level supporting Zama (1991) and Osei (2009) who appreciate the fact that children as young as 7 years in Sweden are given compulsory sex education in schools, most of them (70\%) support sex education at the high school level. In their study, Pauluik et al (2001) suggested that most parents are not aware of the importance of commencing sexual discussions in the early years of a child's development for the establishment of a strong foundation for open discussion in adolescence. Pauluik and associates (2001) have also indicated that health educators argue that it is never too late to start talking about sexual matters with your children; however, having only the "Big Talk" at puberty is often embarrassing and uncomfortable for both the adolescent and parents and much of the information is not absorbed. 
In their study, Sieswerda and Blekkenhorst (2006) identified three stages that parents in their Ontario study initiate sexuality matters with their children. The early initiators indicated that they began sex education with their children at or before the age of 7 years, the second group, consisting of the majority of parents, revealed that they intended to or had actually begun sex education in the preadolescent and adolescent stages of life, and the third group comprising those parents who indicate an intention to discuss sexual matters with their children, but are not certain at what age to commence. The findings of these studies corroborate with this study in that most parents are willing to discuss sexuality with their children at or near puberty. This study has therefore filled the gap in previous studies that have simply generalized parents as supporting sex education at the elementary school level. Seeing that even at the elementary level, many parents prefer sex education for those in the upper primary than at the lower primary levels.

The third hypothesis that suggests that mothers will have more favourable attitude towards sex education than fathers at the lower primary was not supported since the result was not statistically significant. Although, mothers have more favourable attitude towards sex education than fathers, the difference in their respective means was not significantly different from zero. Also when asked how comfortable they were talking about sex with their children, 51.7\% mothers and $46.7 \%$ fathers said they were comfortable talking about sex with their children whereas $53.3 \%$ of fathers and $48.3 \%$ mothers were not. Consequently, only $8 \%$ of fathers as against $27 \%$ of mothers often talked to their children about sex. $54 \%$ of fathers and $38 \%$ of mothers had never spoken to their children about sex. Somers and Gleason (2001) and Kunene (1988) had similar results in their studies on sex education. Obuasi being a mining town with $42 \%$ of the sample working in the mine, fathers possibly spend less time at home and so may have less interaction with their children. Nonetheless, mothers are traditionally more active in child upbringing and see such issues as their responsibility, especially to their daughters. Also, girls spend more time with their mothers in the kitchen whilst boys are usually out playing football and are only called home when food is ready. This fact often remains till adulthood. In addition, sex education has usually focused on females than males and would probably remain same if not for the mutual danger of sexually transmitted infections, particularly AIDS. Except that, most victims of reported sexual abuse are unfortunately females. The finding has also shown that both mothers and fathers see sex education as a joint responsibility between both parents. This finding is consistent with other studies (e.g., Fox, 1989; Marie Stopes International, 2000) that have shown that modern parents have taken a more liberal view of sex education as compared to their parents. According to Sieswerda and Blekkenhorst (2006: 23) "Many parents have come to recognize that sex education delivered by both parents carries an implicit message: that sex is an open topic that can be discussed in the home by both men and women."

The fourth hypothesis that states that mothers would communicate more with their children on sexual matters was supported since the frequency distribution shows that mothers talk more with their children on sexual issues than fathers. This finding is consistent with previous studies that have suggested that mothers tend to provide most of the sexual education of their children, and are also seen by their youth to be more emotionally accessible, capable and knowledgeable about matters that relate to sex (e.g., Rosenthal et al, 2001; Downie \& Coates 1999; King \& Lorusso, 1997). The need for parents, regardless of the gender to discuss sexually related matters with their children is very important since children, especially adolescents desire it. In a study by Werner-Wilson and Fitzharris (2001), adolescents expressed a desire for more communication with their parents on sexual health matters and named their parents as having a profound influence on their sexuality, although, these discussions were seen as uncomfortable.

The fifth hypothesis that states that urban parents would have a more favourable attitude towards sex education than rural dwellers was not supported by the data. Although, urban dwellers appear to have a more favourable attitude towards sex education than rural dwellers, the difference was not statistically significant. This finding is contrary to the finding by (Majija, 1998; Ndlangisa, 1999; Majova, 2002) that parents in urban settings discuss sex-related topics with their children more than parents in rural settings. According to Macleod (1999), rural adolescents have greater sexual knowledge than urban counterparts with age as a co-variate. This is possibly because rural children generally spend more time with their parents than urban 'workaholic' parents do. Also, rural parents are more conservative and may still hold allegiance to age-long taboos (Oppong, Oppong, \& Odotei, 2006; Brocato \& Dwamena-Aboagye, 2007; Ankomah, 2001) passed on from generations than urban parents. On the flip side, urban parents may have more favourable attitudes because urban children are more exposed than rural children who may not have access to computers, television, magazines as they are at the immediate disposal of urban children.

Finally, the hypothesis that states that parental level of education would determine parents' attitude towards sex education was supported by the data. The result shows that parents who have attained tertiary education have a more favourable attitude towards sex education as compared to those who have secondary and lower education. This finding corroborates the finding of Conger (1991) that variables such as academic self-esteem and economic class and highly educated parents position produced liberal attitudes towards sex.

Although the study has produced interesting findings, it was not without limitations. The study was conducted in the late afternoon and some parents were in a hurry to go home because the PTA exceeded the time by $45 \mathrm{mins}$. In Dompoase for instance, most of the parents had returned 
from work so they were tired and this could affect the results. The research respondents were parents from the Obuasi municipality alone, a larger sample size involving other areas would have been more representative of the population. Care must therefore be taken when generalizing the findings beyond this population.

Again, most parents were confused about what sex education was, the mere sound of it kept some parents thinking that we wanted to teach their children how to have sex. This was very difficult knowing that explanations could alter parents' opinions.

The findings of this study provide the platform for influencing policy directions and practical interventions in helping our children to have a positive and informed attitude and appreciation towards sex. The following recommendations are therefore proposed: First, there is a need for professionals like community and educational psychologists to carry out health promotion programmes to empower and educate parents on the importance of timely sex education, its contents and how to go about it. Parents are themselves ignorant about what sex education is about, and this in many ways enhances opposition to it.

Second, for the teachers who will be involved in the education process, in-service education should empower teachers with skills to handle the subject of sex education with confidence.

Third, for the appropriate time for sex education, it is worth noting that averagely these children are 8 years and over. And as the literature shows, this age is the onset of many early sex cases in children. Therefore age appropriate-sex information must be given to children from an early age. This will provide the foundation on which more complex knowledge can be built over time.

Fourth, most parents recognized that peers are a wrong source of information and this cannot be under emphasized. By this age, children would have formed their own theories on matters that concern sex. If parents are unapproachable, children will turn to other sources like friends, and the torrent of uncensored information from the internet, TV, magazines etc for information on sex that may not be reliable. School-based sex education is an avenue for changing these misconceptions and getting answers to their confusing questions.

Fifth, policies on sex education must be based on empirical evidence and not assumptions. More studies on sex education must be conducted to help in informed decision making. The school syllables must include all the various topics that must be discussed and in some details so that teachers do not over give or under give sexuality based information to children.

Sixth, efforts to sensitize people on the need to provide sex education and the risks involved in early sexual activities like AIDS, teenage pregnancy resulting in school drop outs or even abortions leading to death must reach everyone no matter the place of residence. The mass media will play a key role here. The message should be directed at all and not only women.
Seventh, parents must find out what sexuality education the school provides and support them in the provision of age-appropriate sex information at home.

Finally, traditional norms also need to be amended so that sex-related matters can be discussed at will. The responsibility of parents to sex-educate their children should not be left to print media sources such as magazines and books, the internet or friends. It is only when parents are frank and willing to enlighten their children on their sexuality, that they will have correct information and knowledge about sex and appreciate the need to keep away from it until marriage.

\section{Conclusion}

The study has provided an empirical basis, and not societal opinion about the attitude of Ghanaian parents towards sex education at the lower primary level of schooling. As in many areas of research, the area of sex education is particularly important to national progress. As an aspect of development, denying its relevance in society will be counterproductive. Education of all sorts should be beneficial to the individual who is being educated and should in many ways bring a positive impact to the community and the society at large.

Obviously, sex is a sensitive topic in our society and we must make sure that parents are involved in the dialogue on sex; especially the age sex education should start in school. Although the study has brought to the fore that parents do not subscribe to sex education at the lower elementary school level, they nonetheless favour sex education at the upper primary level. This therefore underscores the relevance of sex education to parents in the country.

The fight against HIV/AIDS, teenage pregnancy, and teen abortion that comes with over population and a higher rate of illiteracy, ignorance, and poverty is actually a battle against misconceptions about this topic that people have held on to so tight over the years that they will not let go. In Western societies, sex is the popular subject (Klemp, Moore, \& Moore, 2003) and a similar practice can and must be replicated in our society.

It must be emphasized that in our quest to fostering the sexual development of our children, relevant factors like culture, religion, societal norms and values should be considered. In advocating for sex education we must not throw away the very rich aspects of our society like the decency and modesty that morals add to our culture.

To achieve this, the misconception that sex education to children makes them immoral should change since it is not premised on informed empirical data, but on unverified opinions and assumptions. In a review of 48 studies of comprehensive sex and STD/HIV education programmes in US schools, strong evidence was discovered that such programmes did not lead to a surge in sexual activity. What is true is that some of them decreased sexual activity, or increased the rate of condom usage or other contraceptives, or both (Kirby, 2007). 
Although the findings, in the view of majority of the parents do not support sex education at the lower primary level, their proffered reason that "the children are very young" is not convincing enough. Sexual development is a facet of development, and therefore when it is appropriately introduced to children, even preschoolers; it will help in contributing to the understanding of their sexuality. We should also fathom that if we do not teach our children the right way somebody will teach them the wrong way.

\section{References}

[1] Ankomah, A. (2001). The International Encyclopedia of Sexuality: Ghana. Robert T. Francoeur (Ed.). New York: Continuum.

[2] Ansah-Addo, H. (2005). Adolescent sex on the increase in Ghana: Behind the Mask: Retrieved from ashesi.edu.gh/images/academics/writing/center/09_osei_ess ay.pdf: 28/09/2011.

[3] Athar, S. (1996). Sex education, teenage pregnancy, sex in Islam and marriage. Sex education: An Islamic perspective (pp. 1-20). Chicago, IL: Kazi Publications.

[4] Baron, R.A. \& Byrne, D. (1994). Social psychology: Understanding human Interaction. Boston: Ally Bacon.

[5] Billy, J.O.G., Brewster, K.L. \& Grady, W.R (1994). Contextual effects on the sexual Behaviour of Adolescent woman. Journal of Marriage and the Family, 56(2), 387404.

[6] Briggs, F. (2005). Ignorance is not innocence: why talk about sexuality and prevention of sexual assault in the early years. A keynote speech delivered at family planning Queensland's occasional Wendy Darvill forum. www.fpq.com.au/pdf/WDForum_BriggsSpeech.pdf

[7] Brocato, Vanessa, \& Dwamena-Aboagye, A. (2007). Violence against Women \& HIV/AIDS. Yvette Amissah, et al. Achimota (Eds.): The Ark Foundation Ghana.

[8] Conger, U. (1991). Adolescence and youth psychological development in a changing world. New York: Harper Collins.

[9] Downie, J., \& Coates, R. (1999). The impact of gender on parent-child sexuality communications: has anything changed? Sex Marital Ther, 14(2) 109-121.

[10] Forrester, S. (2009, August 06). Sex education that works. Retrieved from http://www.avert.org/sex-education.htm.

[11] Fox LS (1989). Baby boom parents answer their children's questions on reproduction. Fam Life Educ., Fall, 15-17.

[12] Gallagher, J. \& Gallagher, A. (1996). A young women's guide to teenage sexuality. New York: Harper Collins.

[13] Hovell, M. (1994). Family influence on Latino and Anglo adolescents' sexual behavior. Journal of Marriage and Family, 56: 973-986.

[14] Hyder, J.S. \& DeLamater, J. (1997). Understanding human sexuality. Boston. McGraw-Hill.

[15] Jasmine -Sui, D. (1994). Attitude of parents of Adolescent Girls towards imparting Sex education. In Sue, D. (2010).
Parents and Sex Education: Parents' attitudes to sexual health education in Western Australia Schools. La Trobe University.

[16] Kirby, D. (2007). Emerging Answers 2007: New Research Findings on Programs to Reduce Teen Pregnancy - Full Report', National Campaign to Prevent Teen Pregnancy.

[17] Klemp, J., Moore, A., \& Mary, C.M. (2003). The ECK HI 2 Discourses. Minneapolis: ECKANKAR.

[18] King, B. M., \& Lorusso, J. (1997). Discussions in the home about sex: different recollections by parents and children. $J$ Sex Marital Ther, 23(1), 52-60.

[19] Kunene, P. (1988). Teenager's knowledge on human sexuality and views on teenage Pregnancies. Unpublished honors thesis, KwaDlangezwa: University of Zululand.

[20] Marie Stopes International (2000). Parental attitudes to children's sex education. London: Marie Stopes International.

[21] Lim, J., \& Kui, Y. T. (2006, August 21). Sexually speaking. New Straits Times, p. 6-7.

[22] Mack, J. (2011). Institutionalized stigma in Ghana: Stigma, Shame and Sexuality: Gender across borders. Retrieved from www.rhrealitycheck.org/blog/2011/09/21/institutionalizedstigma-ghana on $25 / 03 / 2012$

[23] Macleod, C. (1999). The causes of teenage pregnancy: review of South African research. Part 2. South African Journal of Psychology, 29 (1), 8 -16.

[24] Marion, H., \& McCabe, J.B. (1990). Helping teenagers postpone sexual involvement. Family planning perspectives, $22,21-25$.

[25] Majija, E.N. (1998). The attitudes of teachers, students and parents towards offering sex education. Unpublished B.Ed. dissertation. Umtata: University of Transkei.

[26] Majova, C.N. (2002). Secondary school learners' attitudes towards sex education. University of Zululand. South Africa.

[27] Malajan, P., \& Sharma, N. (2005). Parents attitude towards imparting sex education to their adolescent girls. Anthropologist, 7(3), 197-199.

[28] McKay, A., Pietrusiak, M. A., \& Holowaty, P. (1998). Parents' opinions and attitudes towards sexuality education in the schools. The Canadian Journal of Human Sexuality, 7 (2), 139-145.

[29] Naidoo, P. (2001). Risk Taking Behaviour and Health Promotion amongst youth in respect of Reproductive Health. Journal of Psychology, 17 (1), 1-11.

[30] Ndlangisa. N. J. (1999). Perceptions of adolescents and their parents on the content and source of sex education. Unpublished masters' thesis, Umtata: University of Transkei.

[31] Nokwe, J. K. (1991). The attitudes of teachers and parents towards offering sex education as a separate course in Senior Secondary Schools. Unpublished B.Ed. dissertation, Umtata: University of Transkei.

[32] Oppong, C., Oppong, P.A. \& Odotei, I. K. (2006). Sex and Gender in an Era of AIDS: Ghana at the turn of the millennium. Accra: Sub-Saharan Publishers, 2006. 
[33] O'Regan, K. (2001). Learning to make wise choices: the challenge for education on Sexuality in South Africa. An address delivered at protecting the right to Innocence: Conference on sexuality education, Gallagher Estates, Mildrand.

[34] Osei, A. (2009). Sex Education in Ghanaian Society: The Skeleton in the Cupboard. Retrieved from ashesi.edu.gh/images/academics/writing/center/09_osei_ess ay.pdf. 28/09/2011

[35] Pauluik, P. A., Little, J., \& Sieswerda, L. E. (2001). Teens Perspectives: Preventive strategies for decreasing teen pregnancy in the Thunder Bay District. Thunder Bay: Thunder Bay Teen Pregnancy Prevention Coalition.

[36] Price, J.H., Dake, J.A., Kirchofer, G. \& Telljohann, S. K. (2003). Elementary school teachers' techniques of responding to student questions regarding sexuality issues. The Journal of School Health, 73 (1), 9-14.

[37] Rosenthal, D., Senserrick, T., \& Feldman, S. (2001). A typology approach to describing parents as communicators about sexuality. Archives of Sexual Behaviour, 30(5):463482.

[38] Sanders, S. A. (2008). Human Sexuality. Microsoft ${ }^{\circledR}$ Student 2009 [DVD]. Redmond, WA: Microsoft Corporation.
[39] Sieswerda, L. E., \& Blekkenhorst, P. (2006). Parental attitudes towards sex education in the home: Results of a 2003 parent survey conducted in Thunder Bay, Ontario. Thunder Bay District Health Unit, Thunder Bay, Ontario.

[40] Small, S.A. \& Luster, T. (1994). Adolescent Sexuality Activity: An Ecological, Risk Factor Approach. Journal of Marriage and the Family, 56(1), 181-192.

[41] Somers, C.L. \& Gleason, J.H. (2001). Does source of Sex Education Predict Adolescents' Sexual Knowledge, Attitudes and Behaviours? Education, Summer, 121, 674-681.

[42] Stack, S. (1994). The Effect of Geographic Mobility on Premarital Sex. Journal of Marriage and the Family, 56(1), 204-208.

[43] Steinberg, L. (1996). Adolescent McGraw-Hill: Temple University Retrieved January 28, 2012, from http://www.nst.com.my/Current_News/NST/articles/12bees/ Article/index_html.

[44] Werner-Wilson, R. J., \& Fitzharris, J. L. (2001). How can mothers and fathers become involved in the sexuality education of adolescents? Journal of HIV/AIDS Prevention \& Education for Adolescents \& Children, 4(1), 49-59.

[45] Zama, N. (1991). Attitudes of parents towards teenage pregnancy. Unpublished honours thesis, KwaDlangezwa: University of Zululand. 